\title{
The Role of Ras Proteins in Insulin Signal Transduction
}

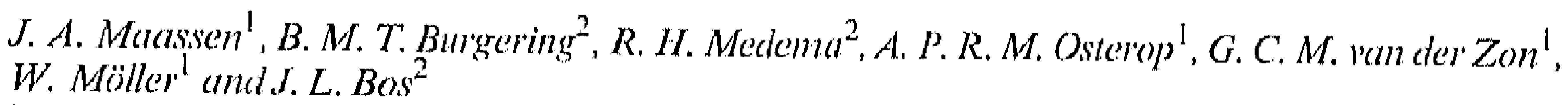 \\ 'Department of Medical Biochemistry, Sylvius Laboratory, Leiden \\ ${ }^{2}$ Department of Physiological Chemistry, University of Utrecht, Utrecht, The Netherlands
}

\section{Summary}

Ras-proteins are guanine nucleotide binding proteins, which, in the GTP bound state emit a strong mitogenic signal. In the GDP bound state, the protein appears inactive. We have found that stimulation by insulin of cells expressing elevated levels of insulin receptors results in a rapid conversion of Ras-GDP into Ras-GTP. This process is part of the signalling pathway leading to immediate-early gene expression and a mitogenic response. There seems to be no involvement of Ras-GTP formation in the process of insulin stimulated glucose transport. Though the precise mechanism by which Ras is converted to the GTP bound state remains to be established, a tight correlation exists between receptor autophosphorylation and Ras-GTP formation.

\section{Key words}

Ras - Insulin Receptor - Mitogenic Response - Glucose Uptake - Insulin

\section{Introduction}

\section{Ras-proteins}

The menbers of the Ras-gene family (H-, Kand N-Ras) all encode related proteins of $\mathrm{Mr}$ of approximately 21,000 (Berbacid 1987). In mammalian cells the Ras genes are a common target for genetic alterations leading to the development of cancer (BOS 1989). Comparative analysis between Ras genes isolated from normal tissue and cancer cells revealed that these alterations were point mutations at one of the positions coding for amino acid 12,13 and 61. The proteins encoded by the Ras genes are guanine nucleotide binding proteins which are located at the inner side of the plasma membrane. Ras proteins share these properties with the $G$ proteins which are well characterized transducers of signals between hormone receptors and the adenylate cyclase system. Because of this resemblance, it was suggested that Ras proteins may act similarly as signal transducers in certain signalling pathways (Scolnick, Papageorge and Shih 1979). Ras proteins bind both GDP and GTP with a similar association constant. In addition, the proteins carry an intrinsic GTPase activity. In the cytoplasm, the concentration of GTP is approximately $10-20$ times higher than of GDP. When the

Horm. metab. Res. 24 (1992) 214-218

(C) Georg Thieme Verlag Stuttgart - New York kinetic constants for GDP/GTP off and on rates and the intrinsic GTPase rate are taken in to account, it can be calculated that most of the Ras should exist in the GTP bound state in cells. This proved to be different. The major fraction of Ras inside colls is in the GDP bound state (Trahey and $M c$ Cormich 1987). The way by which this situation is accomplished is by an intrinsic GTPase activity in the Ras protein which is strongly activated by the cytoplasmic proteins GAP (GTPase Activating Protein) and NF-1 (Trahey and McCormick 1987; Ballester, Marchuck, Boguski, Saulino, Letcher, Wigler and Collins 1990; Martin, Viskochil, Bollag, MoCabe, Croisier, Haubruck, Conroy, Clark, O'Connel, Cawton, Innis and McCormick 1990; Xu, Lin, Tanaka, Dunn, Wood, Gesteland, White, Weiss and Tamanoi 1990). The observation that most of the mutations, leading to oncogenic Ras, increased strongly the fraction of Ras in the GTP form strengthened the idea that RasGTP is the active state and Ras-GDP the inactive form ( $B(n)$ bacid 1987).

While Ras has all the characteristics of a signal transducer the upstream signals, that activate Ras by converting it to the GTP bound state, remain obscure. There are several indications that receptors with a tyrosine kinase activity are located upstream of Ras. The effect of growth factors which activate these receptors is abolished by microinjection of Rals-neutralizing antibodies in cells (Stacey, Tsai, Yu and Smith 1988). In addition, genetic analysis has identified in the nematode $C$. elegans a gene, encoding an EGF like receptor, as an upstream element of Rals (Aroican, Koga, Mendel, Ohshima and Sternberg 1990). Also the way by which Ras-GTP transmits the signal down-stream is unclear. A number of cytoplasmic Ser/Thr kinases are activated by Ras-GTP, like Mapkinase, S6-kinase and the proto-oneogene Raf, Especially Raf seems a candidate for transmitting the signal to the nucleus. In addition, the protein GAP which interacts directly with Ras, maly play a role in transmitting the signal from activated Ras further down-stream (reviewed by Cantley, Auger, Carpenter, Duckworth, Graziani, Kapeller and Solloff' 1991).

\section{The insulin receptor}

The insulin receptor is a transmembrane protein of $\alpha_{2} \beta_{2}$ subunit structure. Insulin binds to the $\alpha$-subunit and induces in the cytoplasmic part of the $\beta$-subunit a tyrosine kinase activity, resulting in autophosphorylation of the $\beta$-chain and phosphorylation of external substrates. Autophosphory. lation occurs both on Tyr and Ser/Thr residues (White and Kahn 1986). The insulin receptor is a member of the large family of hormone receptors with a tyrosine kinase activity. All these receptors have in common the induction of a mitogenic response. A characteristic additional effect of insulin is the 
anabolic action on protein, glycogen and fat and the stimulation of transport processes (e. g. glueose and several anino acids) across the plasma membrane (Rosen 1987). Some insulin receptor mutants have recently been described which show discordant signalling, e. g. the naturally occurring mutant receptor in which Trp 1200 is replaced by Ser, shows normal activation of glycogen synthesis and hexose transport but is inactive in mitogenic signalling (Moller; Benecke and Flicr 1991). This observation suggests that the pathway leading to DNA synthesis is distinct from the signalling process to glycogen synthesis and hexose uptake and that different regions of the cytoplasmic part of the insulin receptor maly couple to different signalling pathways.

The mechanism by which the signals emanated by the activated insulin receptor are transmitted downstream is unclear. The activated insulin receptor Tyr-phosphorylates a subunit of the enzyme phosphatidyl inositol-3-kinase (PI-3kinase), leading to activation of this enzyme, though involvement of this enzyme in a particular signalling pathway has not been established (Endemann, Yonezawa and Roth 1990; Ruderman, Kapeller, White and Cantley 1990). In addition, the activity of a number of Ser/Thr kinases and phosphatases is changed as a result of an insulin stimulus. The activity of these enzymes is modulated by changes in Ser/Thr phosphorylation. Some of these enzymes can be linked to particular effects of insulin. The enzyme S6 kinase may be involved in activating protein synthesis by insulin; MAP-2 kinase seems to play a role in changes in the cytoskeletal architecture and an insulin sensitive kinase regulates glycogen synthesis (Dent, Lavoinne, Nakiclny, Caudwell, Watt and Cohen 1990). As the insulin receptor is a tyrosine kinase, it is not clear how the Tyr-kinase initiates changes in Ser/Thr phosphorylation. It has been shown that upon insulin stimulation particular glycolipids (which also maly be linked to proteins) in the plasma membrane are hydrolyzed, resulting in a hydrophilic oligosaccharide and diacyl glycerol (Romero, Luttrell, Rogol, Zeller, Hewlett and Larner 1988). Both compounds can affect the degree of $\mathrm{Ser} / \mathrm{Th}$ phosphorylation of proteins and thus the activity of $\mathrm{Ser} / \mathrm{Th}$ r kinases and phosphatases. However, the involvement of diacylglyeerol in insulin signalling is controversial as the protein kinase $C$ marker enzyme MARCKS is hardly phosphorylated after an insulin stimulus (Blackshectr, McNoill latupt and Stumpo 1991).

Several lines of evidence indicate a specific involvement of Ras in insulin/IGF-1 action. Oocytes from Xenopus lacvis maturate by incubation with insulin. Microinjection of Ras-neutralizing antibodies inhibits this effect (Korn. Sichel. McCormick and Roth [987). Also the differentiation of 3T3-L1 fibroblasts to adipocytes, which is normally induced by insulin, proceeds autonomously if oncogenic Ras is expressed in these cells (Benito, Porras, Nebrada and Santos 1991).

\section{Involvement of Ras in insulin mediated gene induction}

One of the effects of growth factors is the induction of expression of immediate early genes, like c-fos, cjun and $\mathrm{p33}$. The expression of these genes precedes the onset of DNA synthesis. Insulin is a rather poor mitogen in several libroblast-derived cell lines. We have examined the effect of

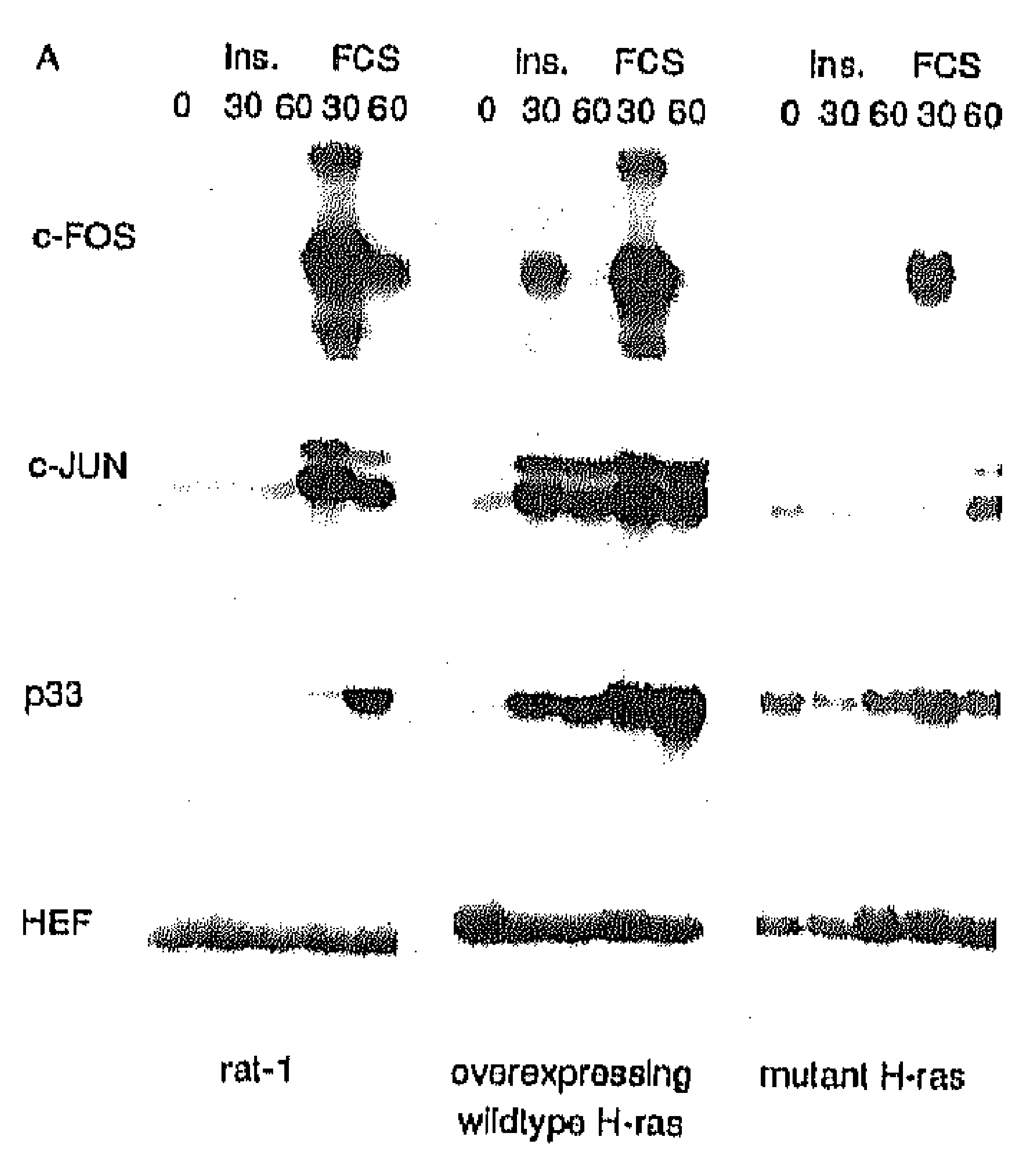

Fig. 1 Induction of c-fos, c-jun and p33 mRNA after growth factor treatment of Rat-1 parental cells and p21 Hras-transformed cell Jines. Subconfluent cultures of dlfferent cell lines were serum arrested for 24 hours and stimulated with insulin (ins, $10 \mu \mathrm{g} / \mathrm{ml}$ ) or fetal calf serum (FCS, 10\%). Total RNA was isolated at the indicated time points and probed for expression of the indicated genes by Northern blot. Hybridization with human elongation factor 1 (HEF) CDNA was performed to indicate equal amounts of RNA.

increasing the number of Ras molecules in the fibroblasts derived cell line Rat-1 on insulin induced mitogenesis and immediate early gene induction. In addition, the effect of expression of oncogenic Ras, i. c. Ras permanently in the GTP form, was examined. In the parental Rat-1 cell, insulin hardly stimulates the expression of the genes fos/jun/p33 (Fig. 1, panelA). That these cells do respond to other growth lactors is reflected by their response toward fetal call serum. When the effect of insulin was examined in Ratt-I cells in which the level of H-Ras was increased by transfection, a clear induction of these genes was observed (Fig. 1, panel B). When Rat- 1 cells were used in which oncogenic Ras was expressed (i. e. Rats permanently in the active, GTP form), no effect of insulin was seen but constitutive increased expression of especially jun and p3.3 was observed (Fig. 1, panel $C$ ). The different cell lines expressed the same number of insulin receptors and also no change in altetophosphorylation activity was seen, excluding a reecptor mediated effect.

Similar results were obtained when ${ }^{3} \mathrm{H}-$ labelled thymidine incorporation was meisured in these cells. Again, Rat-1 cells hardly responded to insulin, whereas colls with high expression levels of WT I-I-Rats showed a near maximal response. $\Lambda$ lso, the cells expressing the oneogenic Ras mutant showed little response to insulin (Burgering. Shijclers;. Maassen, Van der Eb and Bos 1989). These results show that increased expression of $\mathrm{H}-\mathrm{R}$ as results in enhanced insulin receptor signalling, at least via the pathwaly leadling to gene induction and DNA synthesis.

\section{Ras is not part of the signalling patliway to glucose uptake}

To examine the involvement of Rats in stimulation of hexose uptake, insulin stimulated 2-deoxyglucose wis' measured in Rat-1 cells and Rat-1 derived cell lines expressing 
Table 1 Insulin stimulated increase in 12-deoxyglucose uptake by mutant p21ras expressing cells.

\begin{tabular}{lc}
\hline cell line & $\begin{array}{c}\text { increment in } \\
\text { 2-DOG uptake }\end{array}$ \\
\hline Rat-1 & $0.13 \pm 0.02$ \\
H9 & $0.18 \pm 0.02$ \\
H13 & $0.18 \pm 0.03$ \\
RR2 & $0.12 \pm 0.04$ \\
RR3 & $0.11 \pm 0.03$ \\
RR7 & $0.18 \pm 0.05$ \\
\hline
\end{tabular}

${ }^{a}$ Rat-1, parental cell line; $H 9, H 13$, cell lines overexpressing normal p21ras; RR2, RR3, RR7, cell lines transformed by mutant p21ras.

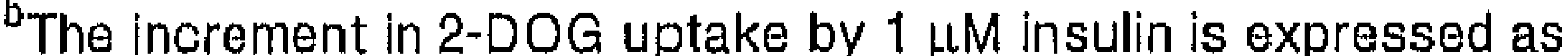
$\mathrm{nmol} / 10^{6}$ cells and is an average of five determinations. Standard de viations are indicated. Basal uptake was approximately $0.3 \mathrm{nmol}$, except in the p21 ras transformed cell lines where basal uptake was 0.6 in RR2, 0.8 in RR3 and $1.4 \mathrm{nmol}$ in RR7 cells.

either oncogenic Ras (i. e. Ras permanently in the active GTP form), or overexpressing WTH-Las. As can be seen in Table 1, all cell lines respond to insulin with a similar increase in 2deoxyglucose uptake, indicating that Ras is not involved in the signalling pathway directed to hexose uptake. It should be noted that cells expressing mutant Ras show much higher basal levels of hexose uptake, due to increased expression of the Glut-1 gene encoding the basal glucose transporter (Flier, Mueckler, Usher and Lodish 1987).

\section{Insulin stimulates the formation of Ras-GTP}

To investigate whether insulin affects the level of Ras-GTP, we analyzed the ratio Ras-GDP/Ras-GTP in unstimulated and insulin stimulated cells. The analysis of the Ras-guanine nucleotide status was according to Downward (Downward, Graves, Warne, Rayter and Cantrell 1990). The principle of this approach is to label cells with ${ }^{32} \mathrm{PO}_{4}$, stimulate the cells with growth factors and to rapidly immune precipitate Ras from the cell lysate. The ratio of labeled GDP/GTP in the immune precipitate is analyzed by thin layer chromatography and autoradiography. We used A 14 cells, an NIH-3T3 cell line expressing approximately $6 \cdot 10^{5}$ insulin receptors as result from transfection with an insulin receptor cDNA expression vector. Stimulation of these cells with $1 \mu \mathrm{M}$ insulin gave a pro. nounced increase in the amount of Ras-GTP (Burgering, Medema, Matassen, van de Wetering, Van der Eb and Bos' 1991). The process was rapid and the maximum level of Ras" GTP was reached after an incubation time of 2 minutes (Fig. 2). To obtain information whether the conversion of Ras into the GTP form is linked to receptor autophosphorylation, Al4 cells were stimulated for 3 minutes with increasing insulin concentrations. The amount of ${ }^{32} \mathrm{P}$ radionctivity in the GTP moiety from the Ras-GTP complex and in the insulin receptor, resulting from autophosphorylation, was determined. When counts due to Ras-GTP were plotted against the radioactivity in the insulin receptor, the relation shown in Fig. 3 was obtained. Initially, a near linear relation between receptor phosphorylation and Ras-GTP formation was observed with a slope of 0.4. As Al 4 cells contain many more insulin receptors $\left(6 \cdot 10^{5}\right)$ than Ras molecules (most parental cell lines have approximately $3 \cdot 10^{4}$ Ras molecules) the relation becomes horizontal when more than approximately $1-2 \cdot 10^{5}$ receptors are atutophosphorylated. From the initial slope of this relation it
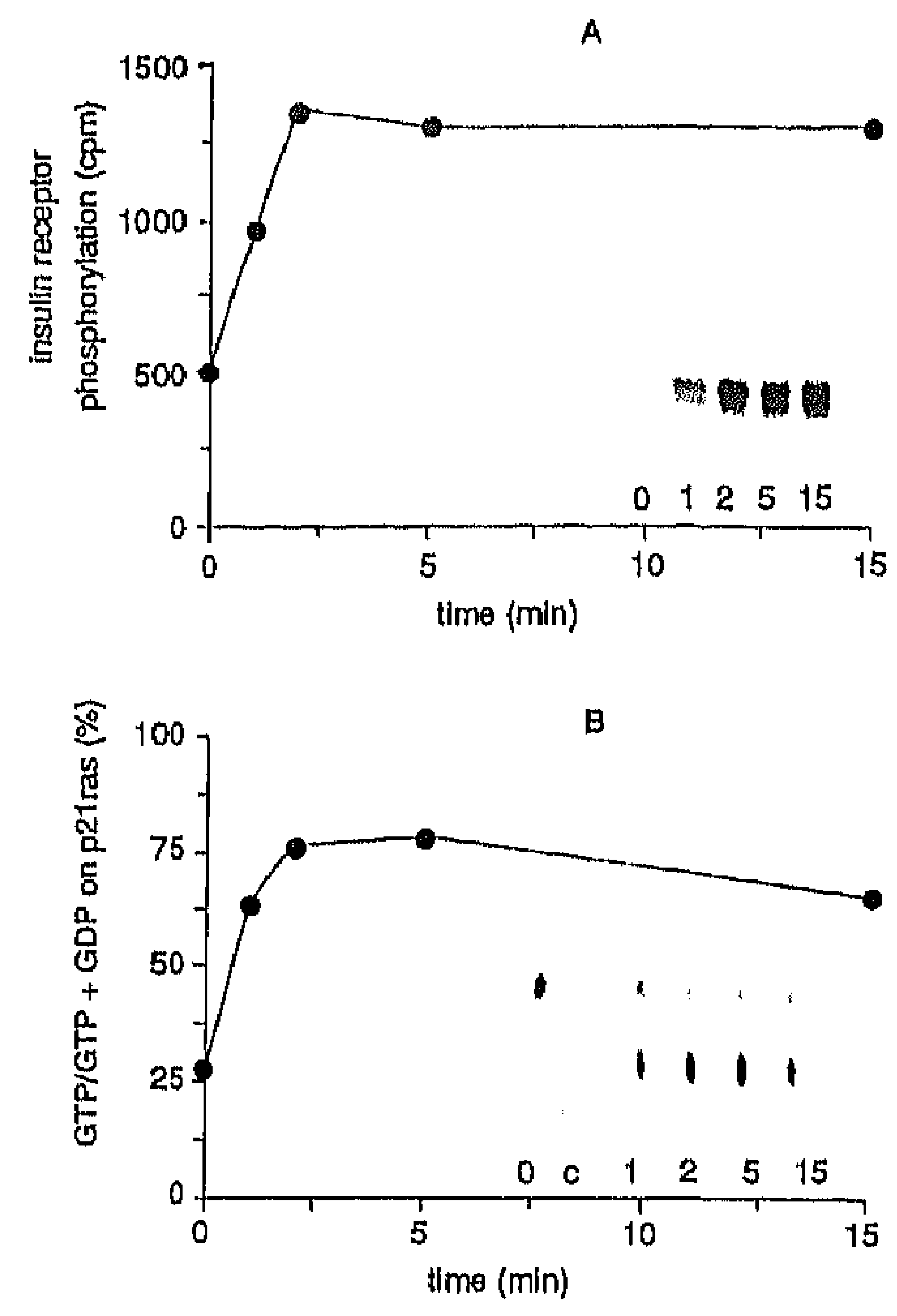

Fig. 2 Time course of insulin induced increase in insulin receptor autophosphorylation (panel A) and increase in GTP bound to p21ras (panel B) after insulin stimulation of A14 cells.

Panel A: Presentation of insulin receptor $\beta$-chain phosphorylation. The insulin receptor was immune precipitated, electrophoresed on reducing SDS-PAGE gels and $\beta$-chain phosphorylation was visualized by autoradiography (insert). The graphic representation shows the quantitated amount of radioactivity in the $\beta$-chain.

Panel B: Graphic representation of the p21rasGTP/GDP ratio in A14 cells after stimulation with insulin for the time indicated. The insert shows the autoradiogram of the thin layer plate separation of GDP and GTP bound to ras. Incubation time is indicated. C: immune precipitation with non-immune serum.

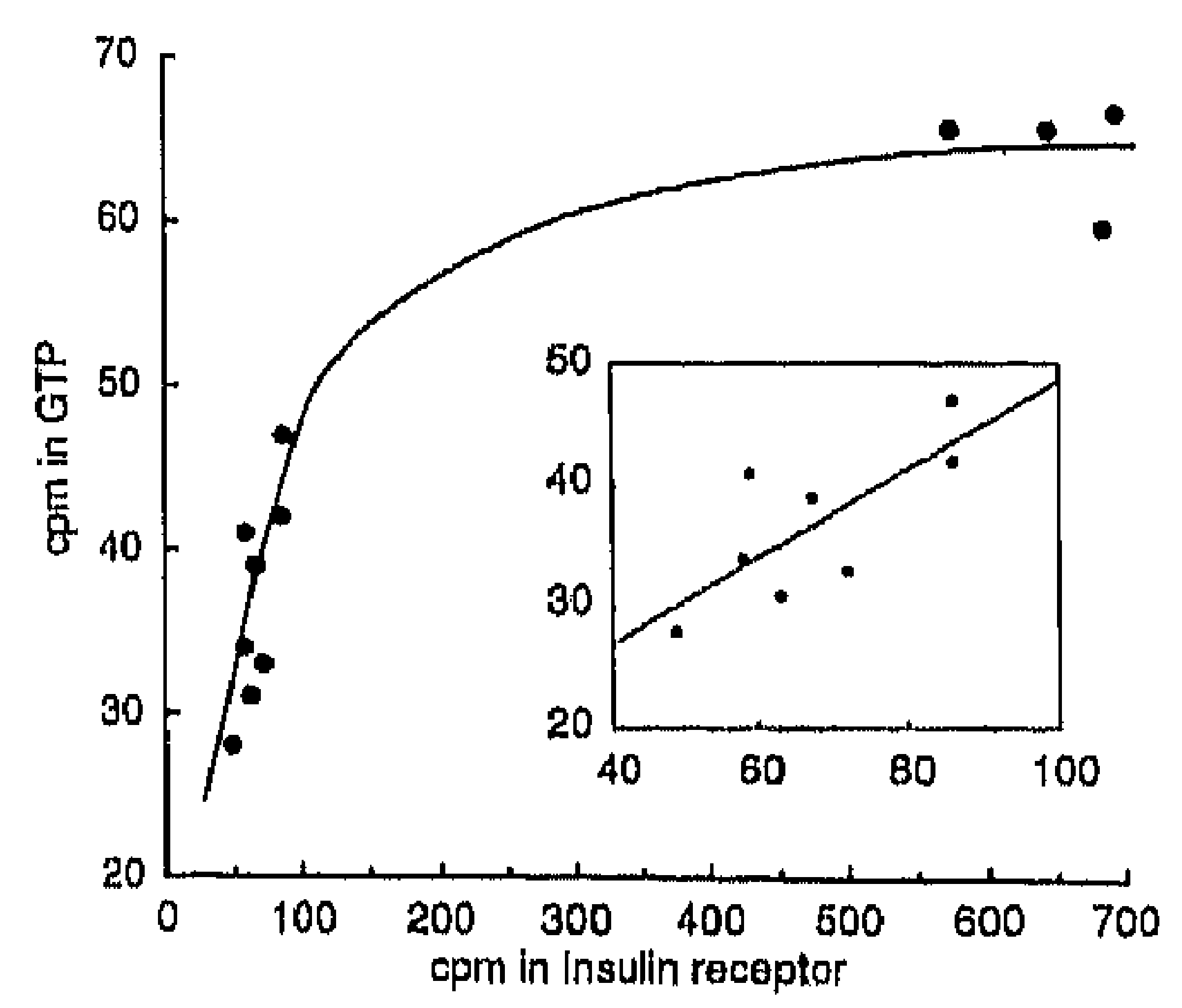

Fig. 3 Relation between receptor autophosphorylation and the amount of Ras-GTP generated. A14 cells were stimulated for three minutes with increasing insulin concentrations and the amount of radioactivity in Ras-GTP and the insulin receptor was determined in each case. The insert shows an expansion of the initial part of the curve.

can be inferred that approximately 0.4 Ras molecules are converted into the GTP form per autophosphorylated (i. e. activated) $\alpha_{2} \beta_{2}$ receptor moiety. For this estimation it is taken into account that $40 \%$ of the insulin stimulated increase in receptor labeling is due to Tyr-phosphorylation and that three Tyr re- 
sidues are predominantly labeled. Furthermore, the specific activities of the $\beta$ and $\gamma$ phosphate of GTP and the phosphates on Tyr are equilibrated under the experimental conditions.

A similar relation as seen with A 14 cells was obtained with $\mathrm{CHO}$ cell lines expressing elevated insulin receptor numbers. In parental CHO cells, expressing approximately 5000 insulin receptors per cell, insulin also increased slightly the Ras-GTP content, from a basal $20 \%$ to $30 \%$.

\section{Discussion}

Two lines of experimental evidence indicate that Ras is part of the signalling pathway of the insulin receptor. First, experiments with cells expressing high levels of HRas or oncogenic Ras suggest that Ras is an intermediate in the signalling pathway leading to expression of the immediate early genes fos/jun/p33 and stimulation of DNA synthesis.

Secondly, experiments with cells expressing elevated levels of insulin receptors show a direct effect on the Ras-GTP status. As Ras-GTP emits a strong mitogenic signal and induces immediate early gene expression, these results stress the model that the mitogenic effect of insulin proceeds via activation of Ras. Ras-GTP formation seems not involved in stimulation of glucose transport.

The observation that insulin stimulates RasGTP formation also in parental CHO cells shows that overexpression of insulin receptors is not a prerequisite to observe this effect. As insulin is not capable of inducing expression of the genes fos/jun/p33 in these cells it suggests that a certain threshold level of Ras-GTP is required for gene induction.

The mechanism by which insulin stimulates the formation of Ras-GTP is yet unclear. It may involve either an activation of the GDP/GTP exchange rate or an inhibition of the GTPase reation, e. g. by inhibiting GAP or NF-1 functions (Fig. 4). Experiments are currently in progress to examine whether insulin affects the kinetics of these processes.

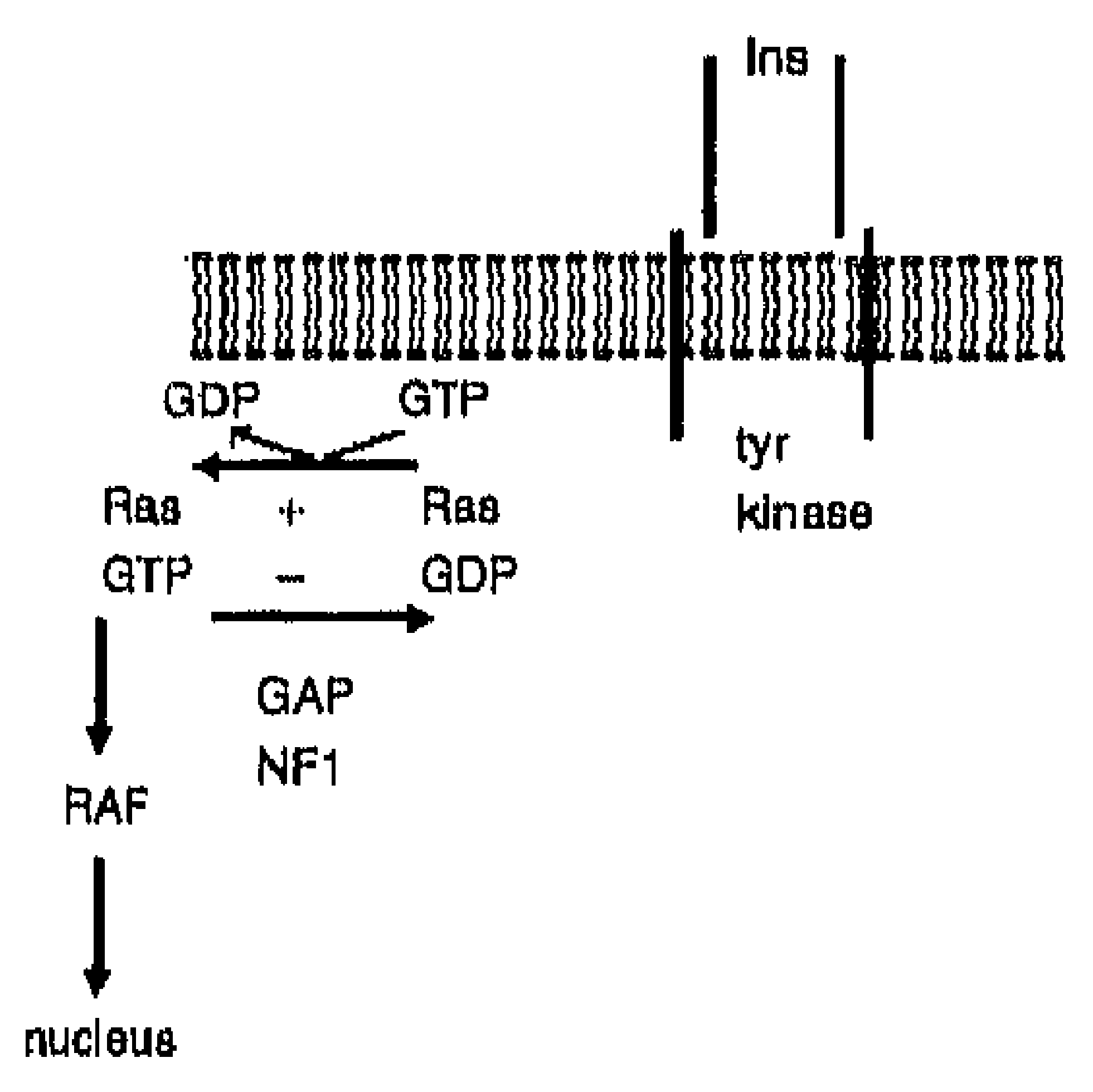

Fig. 4 Representation of the possible mechanisms by which insulin affects the amount of Ras-GTP. The activated insulin receptor either increases the exchange of Ras bound GDP for GTP $(+)$. Alternatively, the stimulation of the intrinsic GTPase activity in Ras by GAP or NF1 may be inhibited (-). Ras-GTP transmits its signal further, probably via the Ser/Thr kinase Raf, to the nucleus.

\section{Acknowledgements}

Cancer Society.

This work was supported by grants from the Duteh

\section{References}

Aroian, R. V., M. Koga, J. E. Mendel, Y. Ohshima Stemberg: The let-23 gene necessary for Caenorhabditis elegans valval induetion encodes a tyrosine kinase of the EGF receptor subfamily. Nature 348: 693-698 (1990)

Baflester, R. D., Marchuck, M. Boguski, A, Saulino, R. Letcher, M. Wh gror, $F$. Collins: The NEI locus encodes a protein lunetionally related to mammalian $\mathrm{GAP}$ and yeast IRA protein. Cell 63: 851-859) $(1990)$

Barbacid, M,: Rals genes. Ann. Rev. Biochem. 50:779-827 (1987)

Benito, M., A. Porres, A. R. Nelmeder, E. Semtes: Differentiation of 3T3-LI libroblasts to adiposytes induced by transformation of ras oncogenes. Science 253:565-568(1991)

Bluckishear, P. J., D. McNeill Haubt, D. J. Stumpo: Insulin activation of protein kinase C: a reassessment. J. Biol. Chem. 266: 10946$10952(1991)$

Bos, J. L.: Ras oncogenes in human cancer: al review. Cancer Res. 49: $4682-4689$ (1989)

Burgering, B. M. T., A.J. Snijders, J. A. Mearssen, A. J. Feander Eh, J. L Bos: Possible involvement of normal p21H-l'as in the insulin/IGF. I signal transduction pathway. Mol. Cell. Biol. 9: 4312-4322 (1989)

Burgering, B. M. T., R. H. Medema, J. A. Maassen, M. L. van de Wetering, A. J. van der $E b, J$. L. Bos: Insulin stimulation of gene expression mediated by p21ras activation. EMBO J. 10: 1103-1109 (1991)

Cantley, L. C., K. R. Aluger, C. Carpenter, B. Duckworth, A. Graziani, R. Kapeller, S. Soltof: Oncogenes and signal tratnsduction. Cell 64: $281-302(1991)$

Dent, P., A. Lav'sinne, S. Nakichn, F. B. Caudwell, P. Watt, Ph. Cohem: The molecular mechanism by which insulin stimulates glyeogen synthesis in mammalian skeletal muscle. Nature 348: 302-308 (1990)

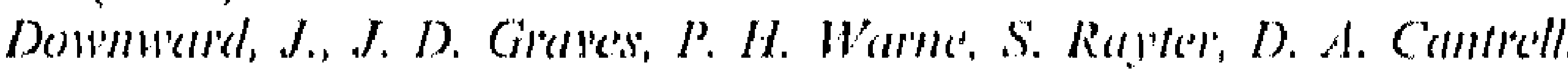
Stimulation of p2 I ras upon T-cell atctivation. Nature 346: 719-723 (1990)

Endemamn, G., K. Yonezawa, R. A. Rorh: Phosphatidyl inositol kinase or an associated protein is a substrate for the insulin receptor ty rosine kinase. J. Biol. Chem. 265:396-400(1990)

Flier, J. S. M. M. Muerkler, I. Usher, H. F. Lotish: Elevated levels of glucose transport and transporter mRNA are ind aced by ras or sre oncogenes. Science 235: 1493-1495(1987)

Kon, L. J., C. W. Sichol, F. MeCormich, R. A. Rollh: Rats p21 as polential medialtor of insulin action in Xenopus oocyles. Science 230: $840-843(1087)$

Martin, C. A., D. Viskexhil, G. Bellegg, P. C. MeCabe, W. I. Crosisier, H. Haubruck, L. Conmeny, R. Clatk, P. O'Commel, R. M. Can'ton, M. A. Imis, $F$. Mecormick: The Gap related domain of the neurotibromatosis type I gene product interats with rats p2l. Cell 63: 84.3849) (1900)

Moller, D. E., H. Benceke, J. S. Fiter: Biological activities ol naturally oceurring human insulin receptor mutations: evidence that medab. olic effects of insulin can be mediated by a kinase deficient insulin receptor mutant. J. Biol. Chem. 266: 10995-1100) I (1991)

Romero, G., L. Lullirell, A. Rogol, K. Zeller, E. Hewlell, J. Larmer: Phosphatidyl inositol-glycan anchors of membrine proteins: potential precursors of insulin mediators. Science 240; 509-511 (1988)

Rosen, O. M.: After insulin binds. Seience 237: 1452-1458 (1987)

Ruclermam, N. B., R. Katerlles, M. F. White, L. C. C(milley: Activaltion of phosphatidylinositol-3-kinase by insulin. Proce. Natl. Acad. Sci. USA 87:1411-1415(1900)

Scolnick, E. M., A. G. Papageorge, T. Y. Shill: Guanine nucleotide binding activity as an assaly for sre protein of at derived murine sarcoma vituses. Proc. Natl. Acacl. Asi USA 76:5355-5350 (1979) 
Stace'y, D. W. M. H. Tsai, O. L. Y'u, J. K. Smith: Critical role of cellulair ras proteins in protiferative signal transduction. Cold Spring Harbor Symposium on Quantitative Biology 53: $871-888$ (1988)

Trahey, M., F. Mc Commick: A cyloplismic protein regulates normal Nrasp21 GTPalse but does not alfect oneogenic mutants. Science 238: $542-545(1987)$

White, M. F. C. R. Kath: The insulin receptor and tyrosine phosphorylation. The Enzymes, vol. XVII Academic Press 247-307 (1986)

Xu, G, B. Lin, K. Tanaka, D. Dunn, D. Wood, R. Gesteland, R. White, R. Weiss, $F$. Tamonoi: The catalytic domain of the neurofibromatosis type 1 sre product stimulates ras GTPase and complements IRA mutants of S. cerevisiate. Cell 63:835-841 (1990)
Requests for reprints should be addressed to:

\section{Dr. J. A. Matasisen}

Department of Medical Biochemistry

Sylvius Laboratory

University of Leiden

Wassenaarsweg 72

NL-2333 AL Leiden (The Netherlands) 